\title{
Coulisses
}

Revue de théâtre

10 | Printemps 1994

Varia

\section{En route pour les rencontres théâtre-université}

\section{(2) OpenEdition}

12 Journals

Édition électronique

URL : http://journals.openedition.org/coulisses/3121

DOI : $10.4000 /$ coulisses.3121

ISSN : 2546-9460

Éditeur

Presses universitaires de Franche-Comté

\section{Édition imprimée}

Date de publication : 1 juin 1994

Pagination : 78-79

ISSN : 1150-594X

\section{Référence électronique}

" En route pour les rencontres théâtre-université », Coulisses [En ligne], 10 | Printemps 1994, mis en ligne le 15 mars 2019, consulté le 31 octobre 2019. URL : http://journals.openedition.org/coulisses/ 3121 ; DOI : 10.4000/coulisses.3121

Ce document a été généré automatiquement le 31 octobre 2019.

Coulisses 


\section{En route pour les rencontres théâtre-université}

1 Les séances ont réuni chaque jour de $10 \mathrm{~h}$ à $12 \mathrm{~h}$ et de $14 \mathrm{~h}$ à $17 \mathrm{~h}$, en général une dizaine de représentants des TU concernés : étudiants, enseignants, metteurs en scènes, et représentante de l'Institut Français de Porto.

\section{Origine du projet :}

2 Une retombée de CYMBELINE, production européenne de 8 théâtres universitaires : Catherine Favret, attachée linguistique à l'Institut des Lettres de l'Université du Minho, stagiaire au C.L.A. en juillet 1993 au moment des répétitions de CYMBELINE a pris contact avec le Théâtre Universitaire de Franche-Comté (T.U.F.C.) pour connaître les modalités de l'organisation de cette création. En octobre 1993, mandatée par le Centre Culturel Français de Porto et les Théâtres Universitaires du Minho (T.U.M.), elle contactait le T.U.F.C. afin de mettre place une co-production franco-portugaise.

Une correspondance suivie et une réunion de travail à Paris permettent de présenter les grandes lignes du projet de co-production franco-portugaise.

\section{Objectifs}

- Pédagogique : Permettre aux étudiants européens de connaître la culture de l'autre par des échanges mutuels de spectacle et par une création commune.

- Artistique: Se trouver confronté à la culture de l'autre, en évaluer les différences de manière à créer un spectacle commun synthétique qui valorise les particularités de chacun.

- Idéologique : Y a-t-il une culture européenne? Comment en prendre conscience, en dépit des différences?

\section{Modalités}

3 Un projet en deux ans :

1993-1994 : Organisation et prise de contact sur deux périodes, février 1994 et juin 
1994 dans le cadre des Vèmes Rencontres Internationales « Théâtre et Université ». 1995 : Création du spectacle ; diffusion au Portugal et en France.

4 Le premier contact avec les TU du Portugal se révélant prometteur, il convenait d'organiser les rencontres de juin 1994 et de prévoir celles d'août 1995, avec en avantprojet les $V^{\text {èmes }}$ Rencontres Internationales Théâtre-Université en Franche-Comté qui concerneront essentiellement les TU du Nord-Portugal et le T.U.F.C. Elles permettront aux TU de présenter leur création :

- WOYZECK de Büchner, TU de Minho (Braga).

- CANDIDE de Voltaire, TU Umbigo (Braga).

- O AUTO DE MOFINA MENDES de Gil Vicente, TU de Porto.

5 Le T.U.FC. présentera ses créations IL ETAIT UNE FOIS, création collective pour Besançon, CHEMINS DE CROIX de Kangni Alemdjrodo, pour Montbéliard.

6 Les matinées seront consacrées à l'organisation de la co-production de 1995, les aprèsmidi à des ateliers dirigés successivement par les metteurs en scène de chaque groupe de manière à ce que chacun expérimente les méthodes de travail de l'autre.

Les «Rencontres" seront soutenues par un programme culturel destiné à faire connaître le Portugal aux Bisontins. Elles sont le fruit d'un partenariat entre les Universités, les municipalités, les associations, les services culturels entre les ambassades. Il en sera de même en 1995, 1a Franche-Comté se présentera au Portugal.

7 Le calendrier, les modalités, l'organigramme, la répartition des charges, ont été l'objet d'un accord. Restent en suspens le sujet de la production, et sa direction artistique... unique ou collégiale.

\section{AFFAIRE A SUIVRE EN JUIN 1994 À BESANCON ET À POURSUIVRE EN 1995 À BRAGA ET À PORTO...}

Rencontres Internationales Théâtre-Université

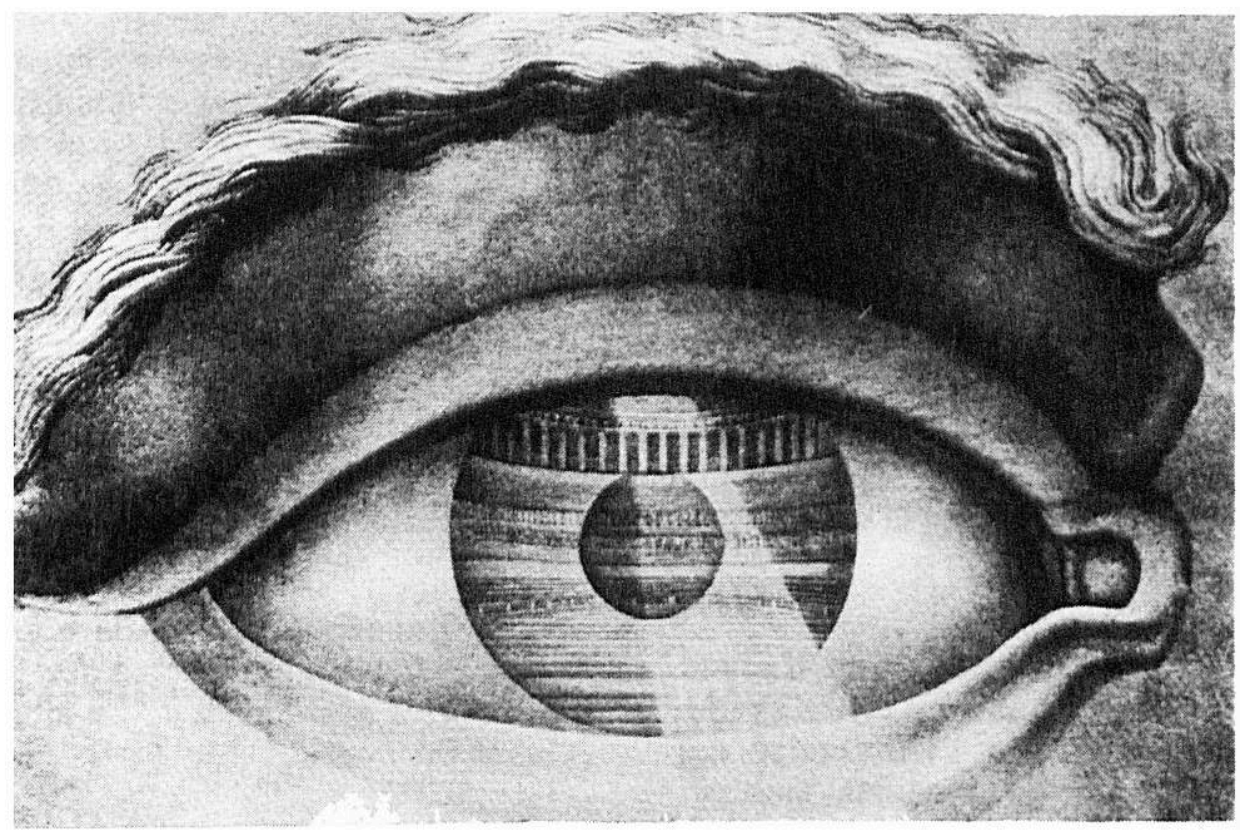

